\title{
Эмиссия и инжекция электронов низких энергий в вакуумных диодах с электродами на основе полупроводниковых гетероструктур с эффективным отрицательным электронным сродством
}

\author{
В.А. Голяшов ${ }^{1,2)}$, Н.А. Назаров ${ }^{2)}$, В.С. Русецкий ${ }^{2,3)}$, А.В. Миронов ${ }^{2)}$, В.В. Аксенов ${ }^{2)}$, О.Е. Терещенко ${ }^{1,2)}$ \\ ${ }^{1}$ Институт физики полупроводников им. А.В.Ржанова СО РАН, \\ 630090, Новосибирск, пр. Ак. Лаврентьева, 13 \\ ${ }^{2}$ Новосибирский государственный университет, 630090, Новосибирск, ул. Пирогова 2 \\ 3 ЗАО "ЭКРАН-ФЭП", 630060, Новосибирск, ул. Зеленая горка 1. \\ тел: +7 (913) 200-2603, эл.nочта: vladimirgolyashov@gmail.com
}

DOI 10.34077/RCSP2019-37

Несмотря на более чем пятидесятилетнюю историю развития фотоэмиттеров с эффективным отрицательным электронным сродством (ОЭС), по-прежнему остаётся много вопросов, как в физике фотоэмиссии, так и в достижении предельных параметров приборов на основе различных полупроводниковых фотокатодов с ОЭС. В частности, интерес представляет получение энергетических и угловых распределений фотоэлектронов, эмитируемых из фотокатодов с ОЭС и построение соответствующей детальной модели процесса эмиссии электронов из области пространственного заряда на поверхности полупроводника с ОЭС в вакуум [1]. Основной проблемой при изучении фотокатодов с ОЭС является очень низкая (до 300 мэВ) кинетическая энергия эмитируемых фотоэлектронов, и, как следствие, сильное влияние любых неоднородностей прикладываемого электрического поля. Эту проблему удается избежать при изучении процессов фотоэмиссии электронов в вакуумных фотодиодах, в которых оба электрода являются полупроводниковыми гетероструктурами с эффективным отрицательным электронным сродством [2]. Кроме того, такие фотодиоды позволяют изучать инжекцию свободных электронов (в том числе поляризованных по спину) в полупроводниковые гетероструктуры.

Фотодиод с двумя ОЭС электродами продемонстрировал способность генерации фототока в широком диапазоне длин волн (350-900 нм) без потенциала смещения. Показано, что значение эффективности преобразования световой энергии в электрическую может достигать значения квантовой эффективности фотокатода, т.е. свыше $50 \%$. Предложен новый вакуумный многокаскадный солнечный элемент с несколькими p-n переходами, разделенными вакуумными зазорами [3]. Измерения энергетических распределений фотоэлектронов при низких температурах подтвердили наличие тонкой структуры в фотоэмиссионных спектрах, связанной с рассеянием электронов на оптических фононах при выходе в вакуум через квантово-размерные состояния в области пространственного заряда.

Методом поляризованной катодолюминесценции (КЛ) изучена инжекция свободных поляризованных по спину электронов в гетероструктуры AlGaAs c квантовыми ямами GaAs. Измерена зависимость циркулярной поляризации КЛ от энергии инжектируемых электронов в интервале 0.5-4 эВ, которая удовлетворительно описывается релаксацией спина по механизму Дьяконова-Переля. Показана возможность измерения пространственного распределения поляризации электронов по одной проекции спина в сечении пучка электронов путем измерения пространственного распределения интенсивности и поляризации КЛ. Обсуждается влияние углового распределения эмитированных из фотокатода электронов на получаемые картины КЛ и возможность восстановления полного их энергетического распределения из картин КЛ.

Работа выполнена при поддержке РФФИ в рамках проекта № 18-02-00353 А.

\section{Лumepamypa}

[1] F. Ichihashi et. al. // Review of Scientific Instruments 89, 073103 (2018).

[2] A.A. Rodionov et. al. // Physical Review Applied 8(3), 034026 (2017).

[3] O.E. Tereshchenko et.al. // Scientific Reports 7(1), 16455 (2017). 